\title{
Approach to Neuropsychiatric Symptoms in Dementia
}

\author{
Ana Luísa Poças* \\ Trainee in Psychiatry, Leiria's Hospital, Portugal \\ Received: April 09, 2018; Published: April 20, 2018 \\ *Corresponding author: Ana Luísa Poças, Trainee in Psychiatry, Leiria’s Hospital, Portugal, Email: analuisapocas@gmail.com
}

\section{Opinion}

Behavior disorders and psychosis can be a greater challenge for patients with dementia and their caregivers. Ninety percent of people with dementia experience behavioural and psychological symptoms such as aggression, agitation and psychosis. These symptoms can be distressing and a threat to the person and their caregivers. In these situations we always tend to medicate after suggesting non-pharmacological measures. The problem often arises after the symptomatology has been stabilized. There are evidence-based recommendations to assess psychological and behavioral symptoms of dementia and perform a risk/ benefit analysis before prescribing an antipsychotic. The Practice Guidelines of American Psychiatric Association (APA) includes recommendations with moderate/low strength of supporting research evidence concerning antipsychotic use to treat agitation or psychosis in patients with dementia [1,2].

The ones with moderate strength are, for example the use of nonemergency antipsychotic medication when agitation and psychosis symptoms are severe, dangerous or cause significant distress to the patient. Another recommendation is that if a risk/benefit assessment favours the use of an antipsychotic for behavioral symptoms, you should start treatment at a low dose and titrate up to the minimum effective dose as if there is no clinically substantial response after a 4-week trial with an adequate dose of an antipsychotic, the treatment should be tapered and withdrawn. The APA recommendations about antipsychotic use also focus that haloperidol should not be used as a first-line agent unless for delirium or in an emergency situation.

Most of the times, the agents continue to be prescribed for months or years after the original symptoms have stopped.
Sometimes doctors, patients and their caregivers are afraid that the symptoms will return.

Most of these patients are elderly people with many health problems, pharmacokinetic and pharmacodynamic changes. They also take multiple medications, increasing the likelihood of drug interactions. It is a special group of patients that requires increased attention but the recommendation of discontinuing antipsychotics after 4 months may seem counterintuitive when the patient is doing well. However the studies showed that a large fraction of

individuals with dementia can discontinue antipsychotics without a return of their agitation or psychosis. For most patients, the risk of harm outweighs the benefits of maintaining treatment, and these patients will never be identified if this discontinuation action is not routinely tried $[3,4]$.

\section{References}

1. The Practice Guidelines of American Psychiatric Association.

2. Victor R, Laura F, A Evan Eyler, Donald M Hilty, Marcela Horvitz Lennonet, et al. (2016) The American Psychiatric Association Practice Guideline on the Use of Antipsychotics to Treat Agitation or Psychosis in Patients With Dementia. The American Journal of Psychiatry 173(5): 543-546.

3. Agency for Healthcare Research and Quality (2015) Methods Guide for Effectiveness and Comparative Effectiveness Reviews.

4. Andrews C, Schünemann J, Oxman AD, Pottie K, Meerpohl JJ, et al (2013) GRADE guidelines: 15. Going from evidence to recommendation: determinants of a recommendation's direction and strength. J Clin Epidemiol 66(7): 726-735. 


\section{(C) (i) This work is licensed under Creative}

Submission Link: https://biomedres.us/submit-manuscript.php

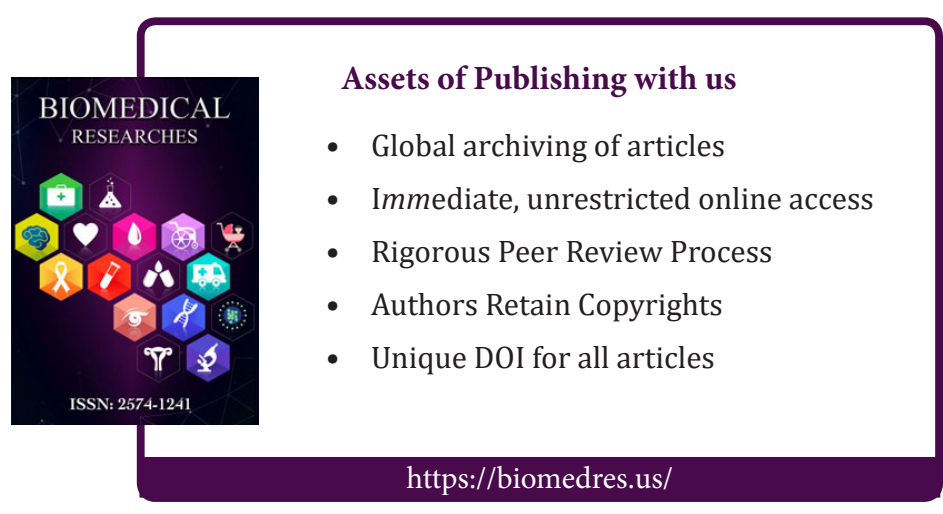

